\title{
Thermodynamic aspects of the self-assembly of DsrA, a small noncoding RNA from Escherichia coli
}

\author{
Frédéric Geinguenaud" ${ }^{1 \#,}$ Maeva Gesson ${ }^{2 \#}$ and Véronique Arluison"2,3* \\ IUFR SMBH, Université Paris 13, Sorbonne Paris Cité, 93017 Bobigny, France; 2Laboratoire Léon Brillouin, Commissariat à l'Energie Atomique, \\ CNRS-UMR 12, CEA-Saclay, Gif-sur-Yvette Cedex, 91191 France; 3University Paris Diderot-Paris 7, Sorbonne Paris Cité, 75013 Paris, France
}

\begin{abstract}
DsrA is an Escherichia coli small noncoding RNA that acts by base pairing to some mRNAs in order to control their translation and turnover. It was recently shown that DsrA is able to self-associate in a way similar to DNA and to build nanostructures. Although functional consequence of this RNA self-assembly in vivo is not yet understood, the formation of such an assemblage more than likely influences the noncoding RNA function. We report here for the first time the thermodynamic basis of this natural RNA self-assembly. In particular we show that assembling of the ribonucleic acid is enthalpy driven and that the versatility of the RNA molecule is important for the polymerisation; indeed, an equivalent DNA sequence is unable to make a nanoassembly. The origin of the difference is discussed herein.
\end{abstract}

Key words: DsrA, small noncoding RNA; nucleic acid self-assembly; RNA nanotechnology

Received: 30 December, 2013; revised: 18 January, 2014; accepted: 20 January, 2014; available on-line: 22 January, 2014

\section{INTRODUCTION}

Small RNAs (sRNAs) are noncoding RNAs involved in regulation of gene expression in bacteria (Storz et al., 2004; Gottesman \& Storz, 2011). We recently showed that, similarly to DNA that is well known to self-associate (Wei et al., 2012), sRNAs are also able to polymerize and that this self-assembly could play a critical role in some important regulatory pathways (Busi et al., 2009; Cayrol et al., 2009). Among them, DsrA, an 87 nucleotides long sRNA, regulates at least two mRNA targets in Escherichia coli. These targets are transcripts of two genes coding for important transcriptional regulators, the stationary-phase and stress response $\sigma^{\mathrm{s}} \mathrm{RNA}$ polymerase subunit (the rpoS gene transcript), and H-NS, a histone-like nucleoid protein and transcriptional repressor (the hns gene transcript) (Lease et al., 1998; Majdalani et al., 1998). The action of DsrA stems from sequence-specific RNA-RNA interactions, as it basepairs with both hns and rpoS mRNAs to affect their translation and turnover.

We observed previously that large DsrA polymers exist, resulting from the auto-assembly of two minimal regions of 14 and 8 nucleotides (nt). This 22 nt region is located in the central part of the sRNA (Cayrol et al., 2009) (Fig. 1A). In particular, nuclease footprinting showed that DsrA monomer can adopt three distinct secondary structures (Majdalani et al., 1998; Lease \& Belfort 2000; Rolle et al., 2006) characterized by two 5' and 3' stem-loops (SL1 and SL3, see Fig. 1A) but with variability in the central region. This variability probably rep- resents the possibility of the SL2 sequence being able to "breathe", thus allowing an intramolecular stem to convert into intermolecular one with another DsrA sRNA (Cayrol et al., 2009; Lease et al., 2012) (Fig. 1B). Furthermore, due to these 14 and 8-nt regions being adjacent, the interaction with another dimer is favored and results in the formation of a polymer (Fig. 1B).

Because the auto-assembly property could have major effects on DsrA functions in vivo, we investigated here the basis of the minimal sequence auto-association. RNA self-assemblies have been previously observed and characterized with artificial sequences specifically designed to self-assemble, creating the concept of "RNA tectonics" (Jaeger \& Chworos, 2006). But this work reports for the first time the thermodynamics of a natural RNA self-assembly. In comparison to protein or deoxyribonucleic self-assembling building blocks, ribonucleic nanostructures combine the advantages of both as it can play a role in the transmission of genetic information or of catalyst. Thus, understanding the basis of the assemblage of natural RNA opens perspectives for the future in vivo developments (Lease, et al., 2012; Afonin et al., 2011).

\section{METHODS}

Synthetic oligonucleotides. Synthetic oligonucleotides were purchased from Eurogentec (Belgium). The following sequences have been used: $\mathrm{DsrA}_{22}{ }^{\mathrm{RNA}}$ AAGUGCUUCUUGCUUAAGCAAG, $\quad \operatorname{DsrA}_{14}{ }^{\mathrm{RNA}}$ CUUGCUUAAGCAAG, DsrA ${ }_{8}^{\mathrm{RNA}}$ AAGUGCUU, DsrA ${ }_{22}$ DNA AAGTGCTTCTTGCTTAAGCAAG, DsrA $_{14}$ DNA CTTGCTTAAGCAAG, DsrA DNA AAGTGCTT', DsrA 22 DNA/GC AAGCGCTTCTTGCTTAAGCAAG and DsrA ${ }_{8}$ DNA/GC AAGCGCTT. Concentrations of oligonucleotides were estimated by UV absorption measurements in water at $20^{\circ} \mathrm{C}$ susing a nearest-neighbor approximation for the absorption coefficients of the unfolded species (Cantor et al., 1970). All nucleic acids concentrations throughout the manuscript will be expressed in strand molarities.

Thermodynamics of nucleic acids self-assembly. The self-assembly of minimal sequences was analyzed by UV spectroscopy. To achieve the measurements, all experiments were performed in $10 \mathrm{mM}$ sodium cacodylate buffer $\mathrm{pH} 7.2$ containing $140 \mathrm{mM} \mathrm{KCl}$ and $10 \mathrm{mM}$ $\mathrm{NaCl}$. Strand concentrations ranged from $0.5 \mu \mathrm{M}$ to 6

e-mail: Veronique.Arluison@univ-paris-diderot.f

\#Equivalent contribution

Abbreviations: bp, base pair; $\mathrm{H}$-bond, Hydrogen bond; nt: nucleotide; ncRNA, noncoding RNA; sRNA, small regulatory RNA; ss/ds DNA/RNA, single/double stranded DNA/RNA; SL, stem-loop; Tm, melting temperature; TEM, Transmission Electron Microscopy 
$\mu \mathrm{M}$. The dependence of UV absorbance on temperature was measured by a temperature-controlled spectrophotometer along heating scans. The rate of temperature change should not exceed $0.5^{\circ} \mathrm{C} / \mathrm{min}$ to guarantee complete thermal equilibrium of the cell. At each temperature, absorbance measurements were done at $257 \mathrm{~nm}$. Data were extracted from the profiles recorded and normalized to $\mathrm{OD}=1$.

The energies involved in self-assembly were determined by a van't Hoff plot, i.e. $\ln \mathrm{K}_{\mathrm{eq}}=\Delta \mathrm{S}^{\circ} / \mathrm{R}-\Delta \mathrm{H}^{\circ} /$ RT. Concentrations of single stranded $\left(\mathrm{C}_{\mathrm{ss}}\right)$ and double stranded $\left(C_{\mathrm{ds}}\right)$ species were calculated from the fraction observed on melting curves as

$\mathrm{C}_{\mathrm{ss}}=\mathrm{f}_{\mathrm{ss}} \cdot \mathrm{C}_{\text {total }}$ and $\mathrm{C}_{\mathrm{ds}}=\mathrm{f}_{\mathrm{ds}} \cdot \mathrm{C}_{\text {total }}=\left(1-\mathrm{f}_{\mathrm{ss}}\right) \mathrm{C}_{\text {total }}$

where $f_{s s}$ and $f_{d s}$ are the fractions of single and double strands, respectively. $C_{\text {total }}$ is the total strand concentration.

For the formation of the duplex, $\mathrm{M}+\mathrm{M} \leftrightarrow \mathrm{M}_{2}$ model was applied $\left(\mathrm{M}\right.$ is the monomer and $\mathrm{M}_{2}$ the doublestranded duplex). The equilibrium association constant $\mathrm{K}_{\text {duplex }}$ is calculated as

$\mathrm{K}_{\text {duplex }}=\left[\mathrm{M}_{2}\right] /[\mathrm{M}]^{2}=\mathrm{C}_{\mathrm{ds}} / \mathrm{C}_{\mathrm{ss}}{ }^{2}=\left[\left(1-\mathrm{f}_{\mathrm{ss}}\right) \mathrm{C}_{\text {total }}\right] /\left[\mathrm{f}_{\mathrm{ss}} \cdot \mathrm{C}_{\text {total }}\right]^{2}=(1-$ $\left.\mathrm{f}_{\mathrm{ss}}\right) /\left(\mathrm{f}_{\mathrm{ss}}^{2} \cdot \mathrm{C}_{\text {total }}\right)$.

For the formation of the hairpin, $\mathrm{M} \leftrightarrow \mathrm{M}$ ' model was applied ( $M$ the single-stranded monomer and $M$ ' the
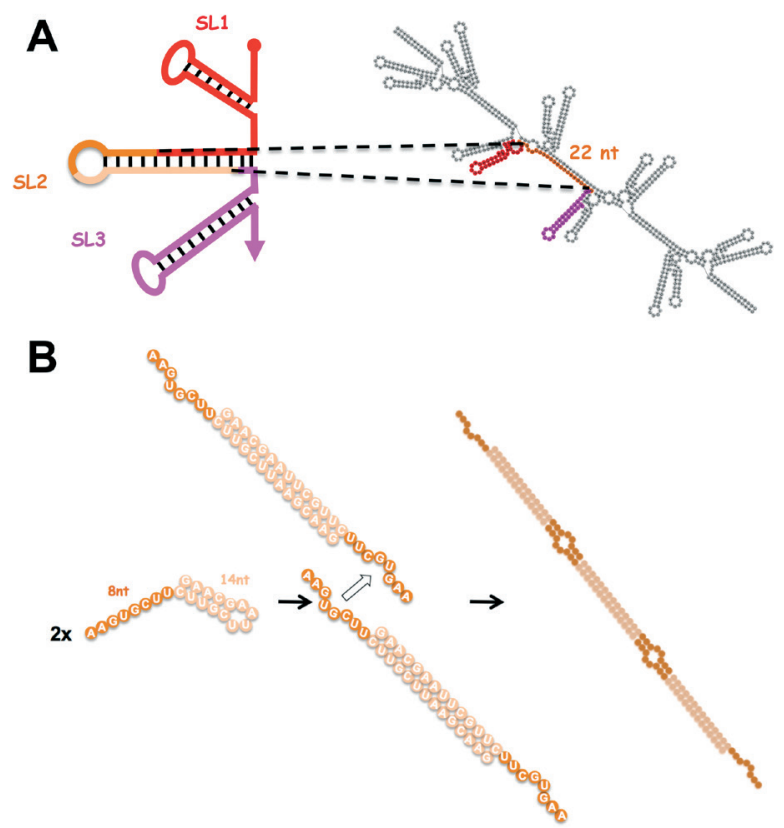

Figure 1. The model for DsrA sRNA self-assembly.

(A) Schematic drawing illustrating how DsrA sRNA self-assembly occurs. The 22 nt central region of DsrA (orange) located between two $5^{\prime}$ and $3^{\prime}$ stem-loops (SL1 in red and SL3 in pink) allows the self-assembly of the whole 87 nt sRNA (Cayrol et al., 2009). DsrA SRNA $5^{\prime}$-end is denoted by a ball and 3 '-end by an arrowhead. Nuclease footprinting shows that this central region can adopt different secondary structures (Majdalani, et al., 1998; Lease \& Belfort, 2000; Rolle, et al., 2006), which probably represents the possibility of the SL2 sequence being able to "breathe", allowing formation of intermolecular base-pairs with another DsrA. (B) Minimal sequence allowing DsrA self-assembly. DsrA self-assembly originates from two adjacent regions of 14 (light orange) and $8 \mathrm{nt}$ (dark orange), resulting in a sequence of $22 \mathrm{nt}$ that could polymerize by itself in the absence of the whole RNA sequence (Cayrol et al., 2009). The 22, 14 and 8 nt sequences of DsrA are annotated as $\mathrm{DsrA}_{22}, \mathrm{DsrA}_{14}$ and $\mathrm{DsrA}_{8}$, respectively, throughout the manuscript. Figure adapted from (Cayrol et al., 2009). double-stranded hairpin). The equilibrium constant $K_{\text {hair- }}$ pin was calculated as

$\mathrm{K}_{\text {hairpin }}=\mathrm{C}_{\mathrm{ds}} / \mathrm{C}_{\mathrm{ss}}=\left[\left(1-\mathrm{f}_{\mathrm{ss}}\right) \mathrm{C}_{\text {total }}\right] /\left(\mathrm{f}_{\mathrm{ss}} \mathrm{C}_{\text {total }}\right)=\left(1-\mathrm{f}_{\mathrm{ss}}\right) / \mathrm{f}_{\mathrm{ss}}$.

In the case of polymerization, the equilibrium can be described by $\mathrm{P}_{\mathrm{n}}+\mathrm{M} \leftrightarrow \mathrm{P}_{\mathrm{n}+1}\left(\mathrm{P}_{\mathrm{i}}\right.$ is the polymer formed by $\mathrm{i}$ subunits and $\mathrm{M}$ the monomer). $\mathrm{K}_{\text {polymer }}$, the equilibrium constant for the association of each subunit to the polymer, can be calculated as

$\mathrm{K}_{\text {polymer }}=\left[\mathrm{P}_{\mathrm{n}+1}\right] /\left[\mathrm{P}_{\mathrm{n}}\right][\mathrm{M}]$ (Fontanille \& Gnanou, 2010).

Taking into account that $\mathrm{P}_{\mathrm{n}}$ and $\mathrm{P}_{\mathrm{n}+1}$ are values at equilibrium, we can consider that for a large polymer, $\mathrm{P}_{\mathrm{n}} \sim \mathrm{P}_{\mathrm{n}+1}$ and that $\mathrm{K}_{\text {polymer }}=1 /[\mathrm{M}]=1 / \mathrm{C}_{\mathrm{ss}}=1 /\left(\mathrm{f}_{\mathrm{ss}} \cdot \mathrm{C}_{\text {total }}\right.$ ) (Fontanille \& Gnanou, 2010).

For all reactions, $\Delta \mathrm{Gr}^{\circ}$, the effective change in standard free energy of reaction, is defined as:

$\Delta \mathrm{Gr}^{\circ}=\Delta \mathrm{Hr}^{\circ}-\mathrm{T} \Delta \mathrm{Sr}^{\circ}=-\mathrm{RT} \ln \mathrm{K}$.

where $\Delta \mathrm{Hr}^{\circ}$ is the change in standard enthalpy of reaction, $\Delta \mathrm{Sr}^{\circ}$ the change in standard entropy of reaction, $\mathrm{R}$ the gas constant and $\mathrm{T}$ the absolute temperature (expressed in Kelvin).

$\Delta \mathrm{Sr}^{\circ}$ and $\Delta \mathrm{Hr}^{\circ}$ were extracted directly from the van't Hoff plot where $\mathrm{R} \operatorname{lnK}$ was plotted against $1 / \mathrm{T}(\mathrm{R} \ln \mathrm{K}$ $\left.=\Delta \mathrm{Sr}^{\circ}-\Delta \mathrm{Hr}^{\circ} \mathrm{x} 1 / \mathrm{T}\right)$, with $-\Delta \mathrm{Hr}^{\circ}$ the slope and $\Delta \mathrm{Sr}^{\circ}$ the intercept at origin of the straight-line. Note that thermodynamic parameters have an incertitude of $\sim 10 \%$ due to the uncertainty for the lower and upper limit of the melting curves.

\section{RESULTS AND DISCUSSION}

\section{Estimating the enthalpic and entropic contributions of RNA self-assembly}

As previously reported (Cayrol et al., 2009), DsrA ${ }_{8}^{\mathrm{RNA}}$ presents an auto-complementary sequence that can selfassemble and form a duplex (Fig. 2, note the presence of 2 G.U wobble base pairs (Varani \& McClain, 2000)). Accordingly, the melting temperature Tm (i.e. the temperature at which half of the DNA duplex will dissociate to become single stranded) observed on the thermal denaturation of $\operatorname{DsrA}_{8}{ }^{\text {RNA }}$ was shown to depend on the strand concentration and thus corresponds to a bimolecular transition (Fig. 2A). Here, we extracted from the melting curves a van't Hoff plot and calculated the changes in standard enthalpy $\left(\Delta \mathrm{Hr}^{\circ}\right)$ and in standard entropy $\left(\Delta \mathrm{Sr}^{\circ}\right)$ of reaction for $\mathrm{DsrA}_{8}{ }^{\mathrm{RNA}}$ duplex formation (Fig. 2B). Our analysis indicates that $\Delta \mathrm{Sr}^{\circ}$ and $\Delta \mathrm{Hr}^{\circ}$ are $-0.75 \pm 0.1 \mathrm{~kJ} \mathrm{~mol}^{-1} \mathrm{~K}^{-1}$ and $-260 \pm 25 \mathrm{~kJ} \mathrm{~mol}^{-1}$ respectively (note that these values are indicative and may vary with experimental conditions; Tm and $\Delta G$ are for instance very sensitive to salt concentration).

Conversely, the thermal denaturation of $\operatorname{DsrA}_{14}{ }^{\mathrm{RNA}}$ shows two transitions (Fig. 3A) (Cayrol et al., 2009). As previously reported, the first transition is clearly concentration dependent and corresponds to an intermolecular association, the self-complementary duplex formed by $\mathrm{DsrA}_{14}{ }^{\mathrm{RNA}}$. By contrast, the second transition is independent of strand concentration and corresponds to the formation of an intramolecular hairpin (Fig. 3A) (Cayrol et al., 2009). Indeed, such a self-complementary sequence commonly adopts two structures: a bimolecular duplex as well as a monomolecular hairpin (Nakano et al., 2007). From the first region of the melting curve, a van't Hoff 

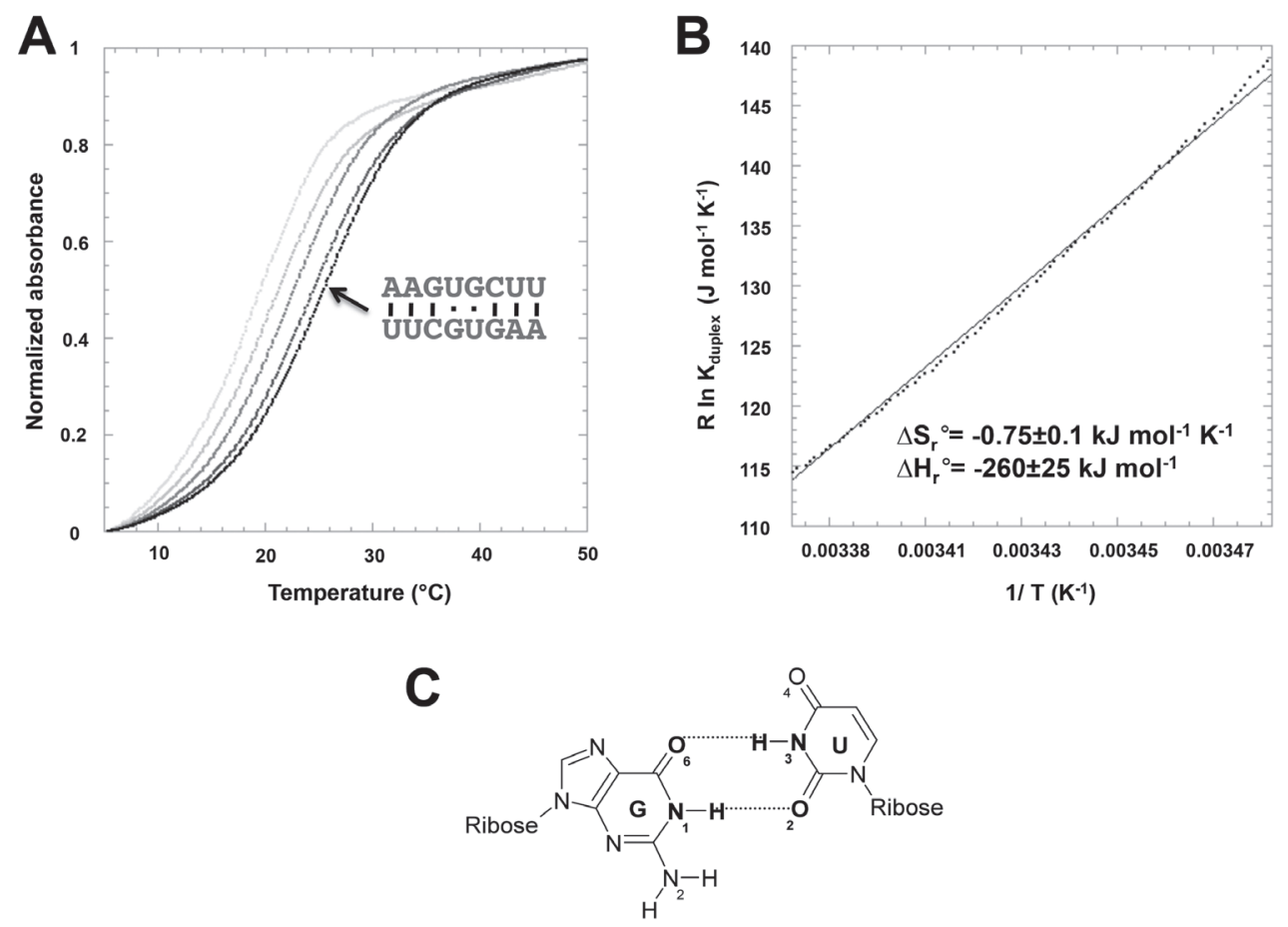

Figure 2. Thermal denaturation of DsrA ${ }_{8}^{\mathrm{RNA}}$.

(A) UV spectroscopic analysis. Absorbance measurements were performed at $257 \mathrm{~nm}$. Strand concentrations ranged from $0.5 \mu \mathrm{M}$ (light grey) to $6 \mu \mathrm{M}$ (dark grey). The reaction is intermolecular as shown by its concentration dependency. The resulting duplex is characterized by a Tm around $20^{\circ} \mathrm{C}$. (B) van't Hoff plot. The thermodynamic parameters are calculated from (A). Briefly, concentrations of single stranded $\left(C_{s s}\right)$ and double stranded $\left(C_{d s}\right)$ species are extracted from the fraction observed on the thermal denaturation curve $\left(f_{s s}\right.$ and $\left.f_{d s}\right)$. $f_{s s}$ corresponds to the distance between the lower baseline and the curve and $f_{d s}$ is the distance between the upper asymptote and the curve. The equilibrium constant is calculated from $C_{s s}$ and $C_{d s}$ as described in methods and the effective change in standard free energy of reaction is calculated as $\Delta \mathrm{Gr}^{\circ}=-\mathrm{RT} \operatorname{In} \mathrm{K} . \Delta \mathrm{Sr}^{\circ}$ and $\Delta \mathrm{Hr}^{\circ}$ are extracted from the van't Hoff plot $\left(\mathrm{R} \operatorname{lnK}=\Delta \mathrm{Sr}^{\circ}-\Delta \mathrm{Hr}^{\circ} \times 1 / \mathrm{T}\right)$. The curve shown corresponds to a concentration of $1 \mu \mathrm{M}$ of strand and mean error from 2 independent samples is indicated. (C) Structure of the G.U wobble base-pair, which is the most common non-Watson-Crick base pair present in RNA (Varani \& McClain, 2000). Part A and C are adapted from (Cayrol et al., 2009).

analysis was made and $\Delta \mathrm{Sr}^{\circ}$ and $\Delta \mathrm{Hr}^{\circ}$ of $\mathrm{DsrA}_{14}{ }^{\mathrm{RNA}}$ duplex assembly were calculated as $-1.2 \pm 0.1 \mathrm{~kJ} \mathrm{~mol}^{-1} \mathrm{~K}^{-1}$ and $-420 \pm 40 \mathrm{~kJ} \mathrm{~mol}{ }^{-1}$, respectively (Fig. 3B). From the second part of the curve, $\Delta \mathrm{Sr}^{\circ}$ and $\Delta \mathrm{Hr}^{\circ}$ for $\mathrm{DsrA}_{14}{ }^{\mathrm{RNA}}$ hairpin formation were calculated as $-0.9 \pm 0.10 \mathrm{~kJ} \mathrm{~mol}^{-1}$ $\mathrm{K}^{-1}$ and $-335 \pm 30 \mathrm{~kJ} \mathrm{~mol}{ }^{-1}$, respectively (Fig. 3C). Note the higher stability of the hairpin (higher Tm resulting in lower $\Delta \mathrm{Gr}^{\circ}$ ) as compared with that of the duplex in our experimental conditions. This has however been previously reported for other RNAs and changes in experimental conditions (especially the concentration of salts) could reverse this tendency (Sun et al., 2007).

Finally, Fig. 4A depicts the melting curve of $\mathrm{DsrA}_{22}{ }^{\mathrm{RNA}}$. As already described (Cayrol, et al., 2009), in spite of the two self-complementary regions, there is only one concentration dependent transition around $40^{\circ} \mathrm{C}$, demonstrating that $8 \mathrm{bp}$ duplex is well stabilized in the context of $\mathrm{DsrA}_{22}{ }^{\mathrm{RNA}}$ polymer ( + about $20^{\circ} \mathrm{C}$ ). The melting of the 8 and $14 \mathrm{bp}$ regions thus occurs simultaneously. From the first part of the van't Hoff plot, $\Delta \mathrm{Sr}^{\circ}$ and $\Delta \mathrm{Hr}^{\circ}$ of $\mathrm{DsrA}_{22}{ }^{\mathrm{RNA}}$ self-assembly can be calculated as $-1.35 \pm 0.15 \mathrm{~kJ} \mathrm{~mol}^{-1} \mathrm{~K}^{-1}$ and $-300 \pm 30 \mathrm{~kJ} \mathrm{~mol}^{-1}$, respectively (Fig. 4B, note that these values characterize the association of one subunit to the polymer).

In all, our analysis shows that the energy associated with DsrA self-assembly is enthalpy driven $\left(\Delta \mathrm{Hr}^{\circ}<0\right)$, while the entropic term $\left(\Delta \mathrm{Sr}^{\circ}\right)$ is negative and unfavorable to the self-assembly. This is not surprising as the entropy change can be largely attributed to the cost of assemblage (i.e. mainly the reduction of the conforma- tional freedom of the phosphodiester backbone), thus entropy favors single-stranded conformation.

\section{Importance of RNA features for the self-assembly}

Next, we decided to test if the RNA feature of DsrA sequence is important for the formation of the nanostructure. Synthetic $\operatorname{DsrA}_{22}$ DNA, DsrA ${ }_{14}^{\text {DNA }}$ and DsrA $_{8}{ }^{\text {DNA }}$ DNA sequences have been used for this goal (uracils were replaced by thymines).

First, we analyzed the self-assembly of $\mathrm{DsrA}_{8}$ DNA. The transition observed on Fig. 5A represents the assembly of the duplex; nevertheless, this duplex is unstable ( Tm $\sim 15^{\circ} \mathrm{C}$ ) and is probably scarce at room temperature. Indeed, it is likely that the difference in stability between $\mathrm{Dsr}_{8}{ }^{\mathrm{DNA}}$ and $\mathrm{DsrA}_{8}{ }^{\mathrm{RNA}}$ duplex results from the formation of a non-Watson-Crick base pair in the RNA oligonucleotide, the G.U base pair (Fig. 2C), that cannot be formed in DNA between $G$ and $T$ bases. To test this hypothesis, we thus tried to restore the 2 central base pairs by replacing the 4th $\mathrm{T}$ of $\mathrm{DsrA}_{8}{ }^{\mathrm{DNA}}$ by a $\mathrm{C}$, thus creating two GC base pairs. This oligonucleotide, called $\operatorname{DsrA}_{8}^{\mathrm{DNA} / \mathrm{GC}}$ (AAGCGCTT) forms a stable duplex as seen on Fig. 5B. The concentration dependency of the $\mathrm{Tm}\left(\sim 35^{\circ} \mathrm{C}\right)$ confirms that the self-assembly corresponds to an intermolecular duplex with this mutation, not to a hairpin (Fig. 5B). We also observe that this duplex is significantly more stable than that formed by $\mathrm{DsrA}_{8}{ }^{\mathrm{RNA}}$ as seen by the higher $\mathrm{Tm}\left(\sim 25^{\circ} \mathrm{C}\right.$ for $\mathrm{DsrA}_{8}{ }^{\mathrm{RNA}} v s \sim 35^{\circ} \mathrm{C}$ for $\left.\mathrm{DsrA}_{8}{ }^{\mathrm{DNA} / \mathrm{GC}}\right)$. However, this difference is not surprising as G-C Watson-Crick base pair 


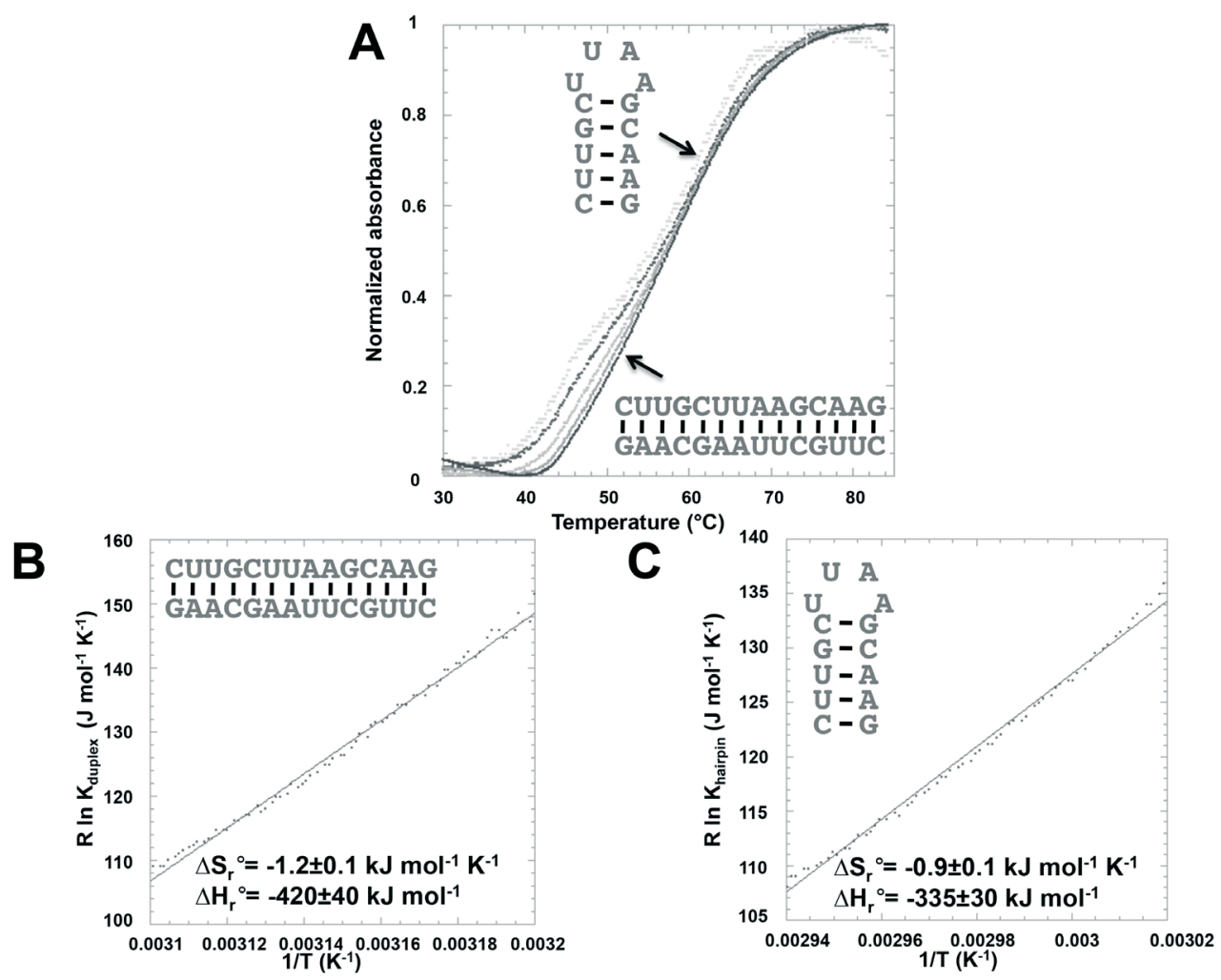

Figure 3. Thermal denaturation of $\operatorname{DsrA}_{14}{ }^{\mathrm{RNA}}$.

(A) The first transition for DsrA ${ }_{14}$ is clearly concentration dependent and corresponds to the intermolecular association of the self-complementary duplex $\left(\mathrm{Tm}\right.$ around $45^{\circ} \mathrm{C}$ ). By contrast, the second transition is independent of strand concentration and is characterized by a $\mathrm{Tm}$ around $60^{\circ} \mathrm{C}$. This corresponds to the formation of an intramolecular hairpin. (B) and (C) van't Hoff plots. Thermodynamic parameters are calculated from $(\mathbf{A})$ and correspond to formation of the intermolecular duplex (B) or to formation of the hairpin (C). As two equilibriums are observed in (A), the curve has been separated into two regions $\left(\sim 35-55^{\circ} \mathrm{C}\right.$ and $\left.55-70^{\circ} \mathrm{C}\right)$, which have been analyzed separately. $C_{s s}$ and $C_{d s}$ have been determined in each case independently for the duplex and for the hairpin and then used for calculation of the $K_{D}$ corresponding to each equilibrium. Part A is adapted from (Cayrol et al., 2009).

A

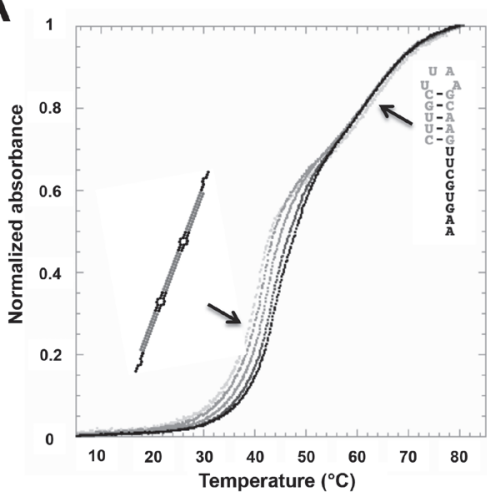

B

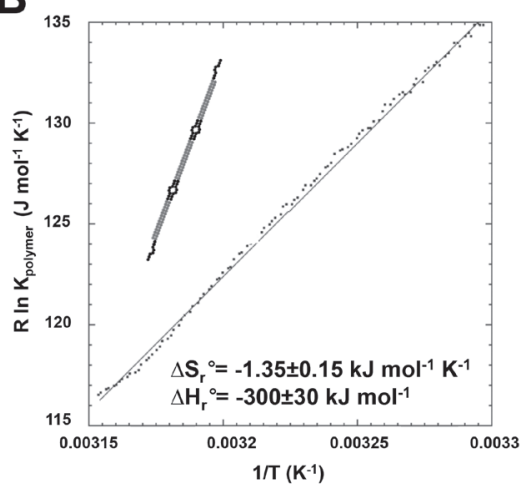

Figure 4. Thermal denaturation of $\operatorname{DsrA}_{22}{ }^{\mathrm{RNA}}$.

(A) In spite of the two self-complementary regions, there is only one concentration dependent transition in the first part of this curve, corresponding to the self-assembly $\left(\mathrm{Tm}\right.$ around $\left.40-45^{\circ} \mathrm{C}\right)$. The dissociation above $40-50^{\circ} \mathrm{C}$ corresponds to the same intramolecular hairpin as that of $\mathrm{DsrA}_{14}\left(\mathrm{Tm}\right.$ around $\left.60^{\circ} \mathrm{C}\right)$. (B) van't Hoff plot corresponding to self-assembly. Thermodynamic parameters are those corresponding to the association of one subunit to the polymer. Part A is adapted from (Cayrol et al., 2009).

(3 H-bonds) is stronger than the G.U wobble base pair (2 H-bonds, Fig. 2C).

Next, we analyzed the melting curve of $\operatorname{DsrA}_{14}{ }^{\mathrm{DNA}}$. As seen on Fig. 5C, this DNA oligonucleotide forms a duplex, but this duplex is not as strong as that made by $D_{s r} A_{14}{ }^{\text {RNA }}$ (compare with the first region of Fig. 3A and the thermodynamic parameters calculated from this curve in Fig. 6C with those of Fig. 3B). However, this result is also not surprising as RNA duplexes are known to be more stable than DNA duplexes, due to a slightly better base-stacking in the A-conformation for RNA base pairing (Ebel et al., 1994).

Then, we analyzed the melting curve of DsrA $22 \mathrm{DNA}$. In this case we observed only one concentration dependent transition around $25^{\circ} \mathrm{C}$ (Fig. 5D). This result was expected taking into account the low stability of $\mathrm{DsrA}_{8}{ }^{\mathrm{DNA}}$ duplex (see Fig. 5A). Indeed, DsrA ${ }_{22}$ DNA is not able to form stable structures similar to those made by $\mathrm{DsrA}_{22}{ }^{\mathrm{RNA}}$ (Cayrol et 


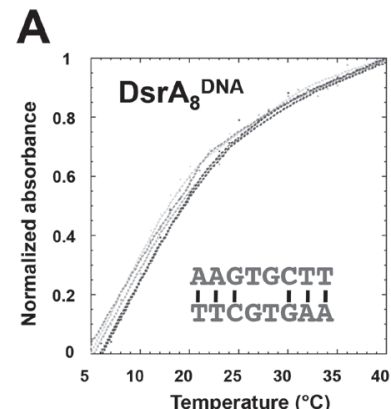

B C
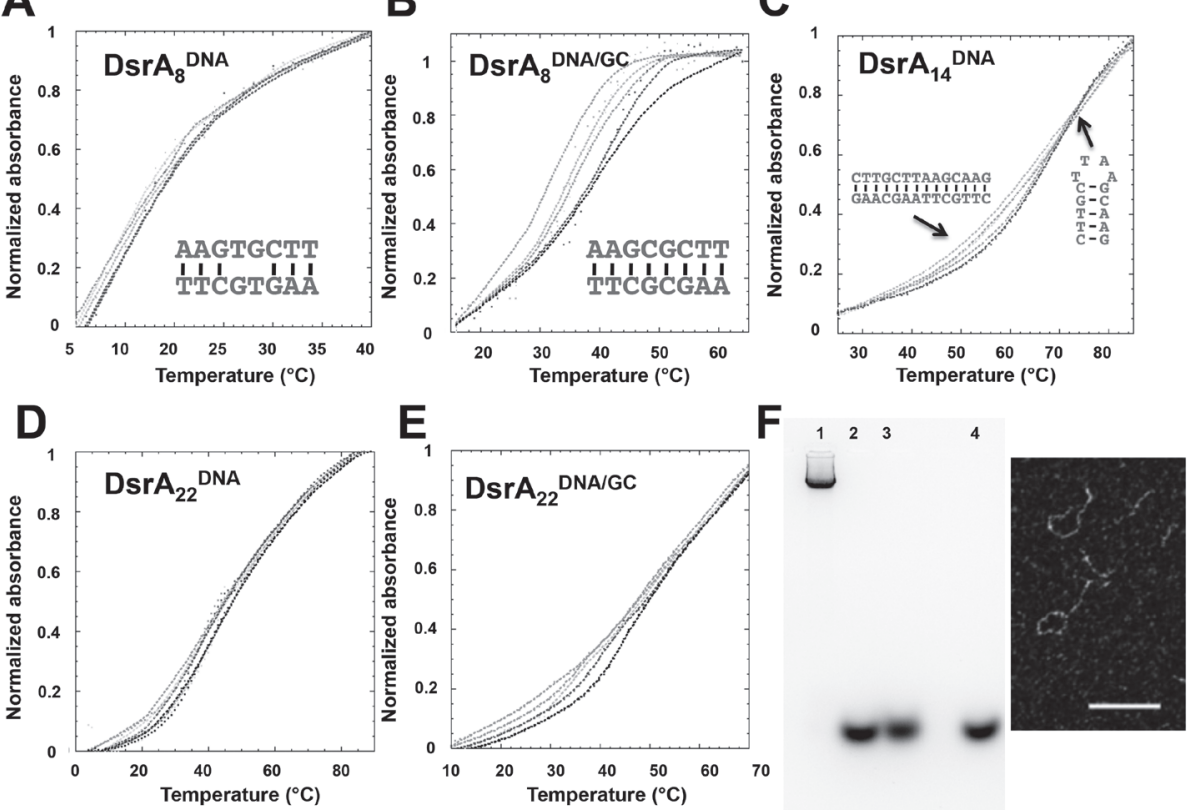

Figure 5. Analysis of DsrADNA sequences self-assembly.

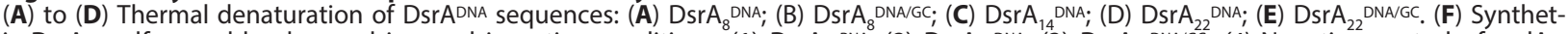
ic DsrA $A_{22}$ self-assembly observed in a gel in native conditions: (1) $\operatorname{DsrA}_{22} \mathrm{RNA}^{8}$; (2) $\mathrm{DsrA}_{22} \mathrm{DNA}^{14}$; (3) $\mathrm{DsrA}_{22} \mathrm{DNA} / G C^{22}$; (4) Negative control of a $\mathrm{dA}_{20}$ oligonucleotide not able to self-associate. As observed in this gel, DsrADNA oligonucleotides are not able to form a stable structure in significant amounts. This result can be confirmed by a TEM analysis. DsrA ${ }_{22}{ }^{R N A}$ spontaneously forms a lot of long polymers (TEM image from (Cayrol et al., 2009)); in the case of $\operatorname{DsrA}_{22}{ }^{\text {DNA }}$ sequence, these structures are extremely rare and cannot be observed readily; this result is in agreement with our gel analysis indicating that $\mathrm{DsrA}_{22} \mathrm{DNA}$ is not able to form such a structure in significant amounts, in contrast to Ds$\mathrm{rA}_{22}{ }_{\mathrm{RNA}}$. Scale bar $100 \mathrm{~nm}$.
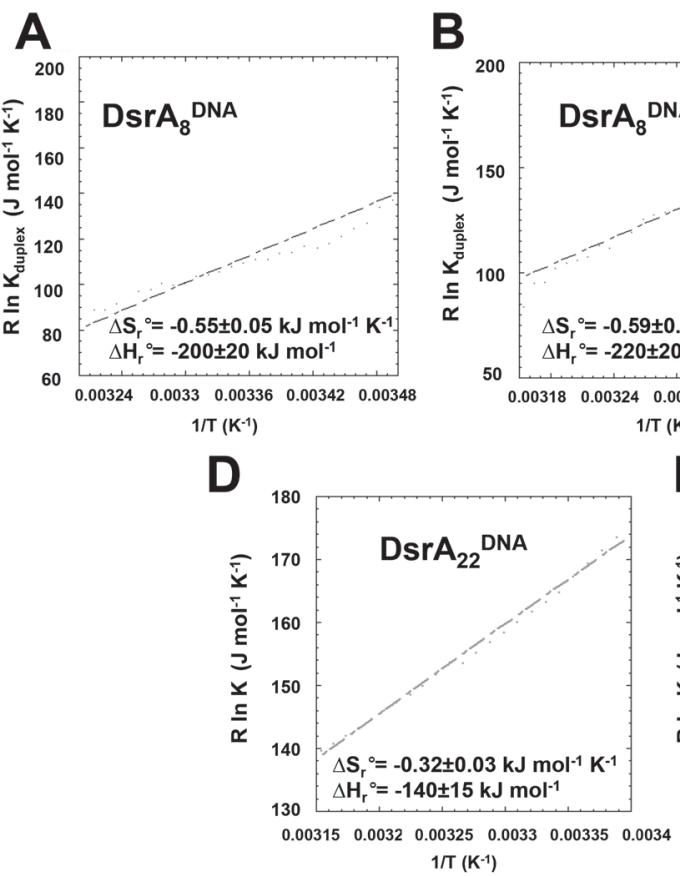

B

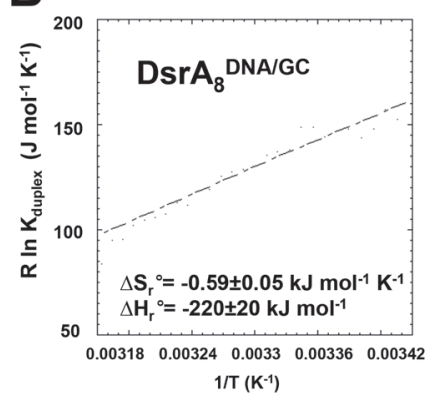

C

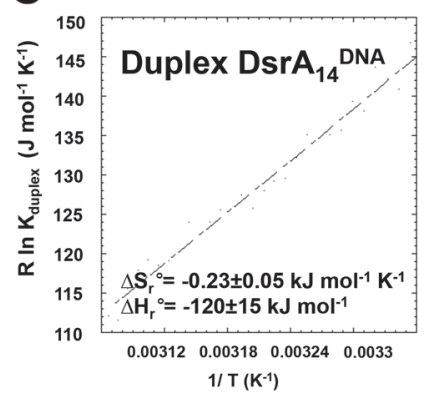

E

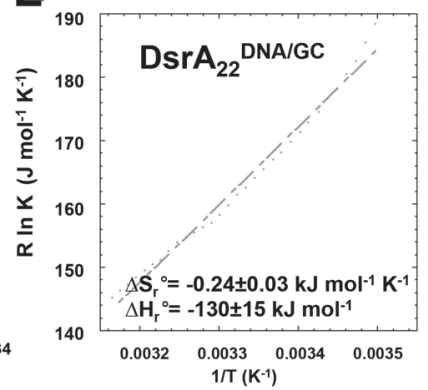

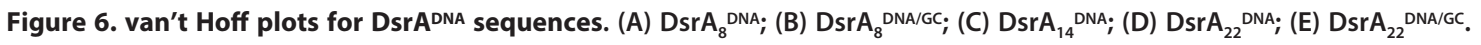

al., 2009), as seen on a native gel (Fig. 5F) and observed by molecular imaging with a transmission electron microscope (TEM). Thus, we tried to see if stabilization of the $8 \mathrm{bp}$ duplex with $\mathrm{G}-\mathrm{C}$ base pairs (equivalent position to that of $\mathrm{DsrA}_{8}{ }_{\mathrm{DNA} / \mathrm{GC}}$ ) could allow the self-assembly. For this goal we used a $\operatorname{DsrA}_{22}{ }^{\mathrm{DNA} / G C}$ oligonucleotide. As seen in Fig. 5E, the melting of the $8 \mathrm{bp}$ and $14 \mathrm{bp}$ regions occurs simultaneously in this condition $\left(\sim 35^{\circ} \mathrm{C}\right)$. Nevertheless, polymers were also not assembled efficiently in this case (Fig. 5F). This implies that reinforcing the stability of the $8 \mathrm{bp}$ region with a dG-dC base pairing does not allow the building of the nanostructure, even if the $8 \mathrm{bp}$ duplex is formed, and that the characteristics of the RNA molecules (A-form or presence of 
non-Watson-Crick base pairs) are also important for the construction of such a self-assembly. Indeed, the versatility of G.U wobble base-pair presumably gives more flexibility to the nucleic acid structure (Demeshkina et al., 2013) and likely favors the self-assembly, which is not possible within an equivalent DNA sequence.

\section{CONCLUSIONS}

The importance of noncoding RNAs in biology has become evident through numerous recent discoveries detailing their control of gene expression, especially in response to stress. We have previously shown that DsrA can self-assemble in vitro, resulting in long fibers that can be observed by molecular imaging (Cayrol et al., 2009). This polymeric structure indeed results from a 22 nt region including two minimal zones of dimerization (one of 14 and one of 8 bp) (Cayrol, et al., 2009). We present here for the first time the thermodynamic characterization of the self-assembly of a fragment of this natural sRNA, in particular the $14+8=22$ nt region responsible of DsrA assembly. Two important conclusions can be drawn from this analysis: (i) the energy associated with DsrA self-assembly is enthalpy driven and relies on the stacking of base pairs one above the other and in the formation of H-bonds between bases. Conversely the entropic term is unfavorable to the self-assembly; (ii) the RNA feature of the nucleic acid is of primary importance for the self-assembly. This results both from the higher stability of RNA duplexes with an A-type helix relative to DNA and from the formation of non-conventional base pairing as the G.U wobble base-pair (Varani \& McClain, 2000). These results thus encourage using ribonucleic acids to build nanostructures for in vivo applications.

\section{Acknowledgements}

We are indebted to $\mathrm{B}$. Cayrol who contributed to this work at an early stage, to R. Guantes, W. Grange, C. Grange, C. Lavelle, O. Piétrement and F. Busi for many fruitful discussions. We are also particularly grateful to J. Teixeira and N. Linder for critical reading of the manuscript.

\section{Acknowledgements of financial support}

This work was supported by CNRS, CEA and University Paris Diderot.

\section{REFERENCES}

Afonin KA, Grabow WW, Walker FM, Bindewald E, Dobrovolskaia MA, Shapiro BA, Jaeger L (2011) Design and self-assembly of siRNA-functionalized RNA nanoparticles for use in automated nanomedicine. Nat Protoc 6: 2022-2034.

Busi F, Cayrol B, Lavelle C, LeDerout J, Pietrement O, Le Cam E, Geinguenaud F, Lacoste J, Regnier P, Arluison V (2009) Auto-assembly as a new regulatory mechanism of noncoding RNA. Cell Cycle 8: 952-954.

Cantor CR, Warshaw MM, Shapiro H (1970) Oligonucleotide interactions. 3. Circular dichroism studies of the conformation of deoxyoligonucleotides. Biopolymers 9: 1059-1077.

Cayrol B, Geinguenaud F, Lacoste J, Busi F, Le Derout J, Pietrement O, Le Cam E, Regnier P, Lavelle C, Arluison V (2009) Auto-assembly of E. coli DsrA small noncoding RNA: Molecular characteristics and functional consequences. RNA Biol 6: 434-445.

Demeshkina N, Jenner L, Westhof E, Yusupov M, Yusupova G (2013) New structural insights into the decoding mechanism: translation infidelity via a G.U pair with Watson-Crick geometry. FEBS Lett 587: 1848-1857.

Ebel S, Brown T, Lane AN (1994) Thermodynamic stability and solution conformation of tandem G.A mismatches in RNA and RNA. DNA hybrid duplexes. Eur J Biochem 220: 703-715.

Fontanille M, Gnanou Y (2010) In Chimie et physico-chimie des polymees. Dunod Ed, Paris.

Gottesman S, Storz G (2011) Bacterial small RNA regulators: versatile roles and rapidly evolving variations. Cold Spring Harb Perspect Biol 3: (a003798).

Jaeger L, Chworos A (2006) The architectonics of programmable RNA and DNA nanostructures. Curr Opin Struct Biol 16: 531-543.

Lease RA, Cusick ME, Belfort M (1998) Riboregulation in Escherichia coli: DsrA RNA acts by RNA:RNA interactions at multiple loci. Proc Natl Acad Sci USA 95: 12456-12461.

Lease RA, Belfort M (2000) Riboregulation by DsrA RNA: trans-actions for global economy. Mol Microbiol 38: 667-672.

Lease RA, Arluison V, Lavelle C (2012) Twins, quadruplexes, and more: functional aspects of native and engineered RNA self-assembly. Front Life Sci 6: 19-32.

Majdalani N, Cunning C, Sledjeski D, Elliott T, Gottesman S (1998) DsrA RNA regulates translation of RpoS message by an anti-antisense mechanism, independent of its action as an antisilencer of transcription. Proc Natl Acad Sci USA 95: 12462-12467.

Nakano S, Kirihata T, Fuiji S, Sakai $H$, Kuwahara M, Sawai H, Sugimoto N (2007) Influence of cationic molecules on the hairpin to duplex equilibria of self-complementary DNA and RNA oligonucleotides. Nucleic Acids Res 35: 486-494.

Rolle K, Zywicki M, Wyszko E, Barciszewska MZ, Barciszewski J (2006) Evaluation of the dynamic structure of DsrA RNA from E. coli and its functional consequences. I Biochem 139: 431-438.

Storz G, Opdyke JA, Zhang A (2004) Controlling mRNA stability and translation with small, noncoding RNAs. Curr Opin Microbiol 7: $140-144$.

Sun X, Li JM, Wartell RM (2007) Conversion of stable RNA hairpin to a metastable dimer in frozen solution. RNA 13: 2277-2286.

Varani G, McClain WH (2000) The G.U wobble base pair. A fundamental building block of RNA structure crucial to RNA function in diverse biological systems. EMBO Rep. 1: 18-23.

Wei B, Dai M, Yin P (2012) Complex shapes self-assembled from single-stranded DNA tiles. Nature 485: 623-626. 